\title{
Fraud offers big rewards for relatively little risk
}

\author{
We need to change the over-competitive culture that promotes publishing at all costs.
}

Sir - Your News Feature "It's a scoop!"

(Nature 426, 222-223; 2003) thoughtfully

explores the dangers of excessive

competitiveness among researchers

racing to be the first to publish high-

profile scientific results. Although this

can lead to secretiveness or sloppy work,

a much worse possibility is that it is

encouraging scientific fraud or other

forms of misconduct.

For example, I asked a colleague who was familiar with the details of a recent case of scientific fraud why - given the risks - he thought the perpetrators had done it. He drolly observed that the real question is not why a few scientists commit fraud, but why more don't do it. He went on to say that since the maximum penalty for getting caught (dismissal) was no worse than the routine penalty for not producing enough high-profile papers (no job), most junior scientists, at least, have nothing to lose by committing fraud. I suspect that, although blatant cases of fraud in high-profile journals are probably rare, more subtle forms may be quite common: skipping a control or two, claiming that the same result was obtained in a repeat experiment that was not made, or failing to mention that some essential cross-checks did not give the required result.

It is almost impossible to determine how often this kind of thing is happening, but that is not a cause for complacency. The notion that fraud will always be detected when the results are shown to be false assumes that the fraudulent results will always stand out sufficiently to attract scrutiny. Less blatant cases may pass unnoticed, or the researcher trying to push his or her work just a little might actually have guessed right. Furthermore, how many researchers these days have time to repeat whole chunks of previously published work, or go back over older literature and critically examine every result for possible signs of fraud, let alone be willing to do anything about such suspicions?

What can be done? It probably requires changes in the way science is funded, and especially how junior scientists are employed. Some sort of international inspection body might help, similar to that used to find and punish cheats in the sporting world. And as individuals, we can all help to develop a scientific culture that discourages fraud or related misconduct as much as possible, while finding ways to increase the rewards for honest but effective competitors.

\section{T. M. Fenning}

Max Planck Institute for Chemical Ecology, Beutenburg Campus, Hans-Knöll-Strasse 8, D-07745 Jena, Germany

\section{Biodefence funds have tight strings attached}

Sir - From reading your News story on the trial of Thomas Butler, "Plague trial verdict leaves biologists split on defence" (Nature 426, 593; 2003), it is not yet clear that US scientists are eager to work on biodefence projects, as suggested by the former president of the American Society for Microbiology, Ronald Atlas. What is clear, however, is that they are eager to get their hands on the flood of new federal money for biodefence research. No doubt the money will be used to finish current research projects, buy new equipment, hire technicians, fund graduate students and impress tenure committees. Only later will they have to consider the burden that comes with that money: regulatory paperwork, conflicting rules and regulations, and the scrutiny of the Federal Bureau of Investigation and other security bureaucrats.

Atlas says he has not seen evidence that new regulations are having an adverse impact on researchers, but that is largely because the ink is not yet dry on many of the new laws and regulations. We will have to wait a few years to see their full impact on academic research.

"We live in a new regulatory environment; it is our responsibility as scientists and citizens to comply with the laws and regulations," writes Atlas. It is also our responsibility as scientists and citizens to question the utility and enforcement of such laws and regulations. As the economist Lester Thurow reminds us (Atlantic Monthly 283, 6; 1999): "being skeptical and refusing to accept authority are the secrets of scientific advancement." Edward McSweegan 1692 Barrister Court, Crofton, Maryland 21114, USA

\section{Bridging a know-do gap}

Sir — Tikki Pang, in Correspondence (Nature 426, 383; 2003) about your Editorial "In praise of Gates" (Nature 425, $435 ; 2003$ ), calls for the Gates Foundation to support the translation of knowledge into actions to improve people's health.

Pang will be pleased to hear that the Gates Foundation is backing one key solution to addressing the 'know-do' gap: education. Among other projects, it is supporting an innovative 'E-learning certification programme in global health' directed at health professionals working in Africa, co-authored by African and international medical scientists and clinicians (see www. tall.ox.ac.uk/ globalhealthprogramme). The aim is to provide research-based and up-to-date information where and when it is needed. The first module will be on malaria.

Sarah Davies ${ }^{\star}$, Abiola Sulaimon $\dagger$

${ }^{*}$ Technology-assisted Lifelong Learning,

Department for Continuing Education, University of Oxford, Littlegate House, Oxford OX1 1PT, UK $\dagger$ Nuffield Department of Clinical Medicine, University of Oxford, John Radcliffe Hospital, Oxford OX3 9DU, UK

\section{Hibben was not proved guilty of misconduct}

Sir - On behalf of the University of New Mexico (UNM), there are three points I wish to make in response to the News story "University buildings named on shaky ground" (Nature 426, 374; 2003) about the UNM Center for Archeological Research and its benefactor Frank Hibben.

First, scientific controversy is the norm, rather than the exception, when it comes to research. It is quite different from scientific misconduct or fraud. Second, as noted in the News story, no allegation of scientific misconduct has ever been filed concerning Hibben's work in any of the venues in which such charges can be filed. Third, in view of the previous points, resurrecting decades-old controversies eighteen months after Hibben's death and characterizing them as fraud is unworthy of Nature. As your News story pointed out, "he was a mentor to many of today's leading US archaeologists, and is widely credited with popularizing modern archaeology".

We feel that these points and his many research and teaching accomplishments put our decision to name the Hibben Center in his honour on solid, not shaky, ground. Terry L. Yates

Vice Provost for Research, University of New Mexico, Albuquerque, New Mexico 87131, USA

Correction P. Kaaret's Correspondence letter (Nature 427, 287; 2004) should have included the expression $\left(\chi<10^{-4}\right)$, not $\left(\chi<10^{4}\right)$. Nature apologizes for this error. 